\title{
Practices and Attitudes About Cathode-Ray Tube-Based and Film-Based Image Interpretation
}

\author{
Bret F. Coughlin, Steven E. Seltzer, Richard G. Swensson, and Philip F. Judy
}

\begin{abstract}
A questionnaire was mailed to 708 practicing radiologists and $\mathbf{3 4 8}$ members of the Society for Computer applications in Radiology (SCAR) in order to evaluate current practices and attitudes regarding the perceived advantages or disadvantages of film- and CRTbased image interpretation. A total of $27 \%$ of the 1,056 questionnaires (137 practicing radiologists; 145 SCAR members were returned. Ninety percent of practicing radiologists used film at least $75 \%$ of the time. Advantages of film-based reading listed by more than $75 \%$ of the respondents included: film reading is faster, and facilitates viewing multiple images. Advantages of CRT-based reading included: access to the entire dynamic range and potential image processing. Desirable attributes of existing displays included: adjustable grey scale, magnification, ability to view multiple images, allow quick review, and viewing by several individuals. Valued potential advances included: multiple higher resolution monitors, image processing and multimodality display. Practicing radiologists and computer applications society members had similar attitudes. Film-based reading is still nearly universal, but radiologists are interested in CRT-based reading if such devices have the proper features and become more available.
\end{abstract}

Copyright 1992 by W.B. Saunders Company

KEY WORDS: image display and recording, images, display, images, interpretation, images, storage and retrieval.

$\mathbf{T}$ ECHNOLOGICAL advances continue to drive the trend toward increased use of cathode-ray tubes (CRT) and electronic image interpretation. The National Science Foundation, the American College of Radiology, and major equipment manufacturers have sponsored workshops on the future of electronic image interpretation..$^{1-4}$ Despite the general acceptance of the importance of the CRT-based interpretation systems, there is little objective information about radiologists' current prac-

From the Department of Radiology, Hanvard Medical School, Brigham and Women's Hospital, Boston, MA.

Supported in part by USPHS Grants RO1-CA40444, PO1CA41167 and T32-CA09536.

Address reprint requests to Bret $F$. Coughin, $M D$, Department of Radiology, Baystate Medical Center, 759 Chestnut St, Springfield, MA 01199.

Copyright 101992 by W.B. Saunders Company

0897-1889/92/0501-0003\$03.00/0 tices and attitudes and about how they compare with those of physicians/scientists who have a special interest in such systems technology. ${ }^{5-8}$ This study surveyed the anticipated users of CRT-based systems (practicing radiologists) about their current practices, and about their attitudes concerning the real or perceived advantages and disadvantages of CRT-based and film-based interpretation systems and compared practicing radiologists' perceptions to the members of the Society for Computer Applications in Radiology (SCAR) who had, by virtue of their affiliation with the organization, demonstrated such a special interest. The goal was to gain information that could help in designing and developing interpretation systems likely to be accepted and valued by radiologists.

\section{MATERIALS AND METHODS}

A questionnaire to evaluate attitudes and current interpretation practices was mailed to two groups. One group was a sample of 708 practicing radiologists, (designated the "PR group"). This group was chosen by selecting every 10 th name from an alphabetized list of just over 7,000 radiologists who had attended any one of over 50 radiology postgraduate courses given over the past 5 years by our university's continuing medical education department. This cohort represented all 50 states; the New England and Mid-Atlantic regions were represented with the highest frequency, with diminishing representation at increasing distances from Boston. The second group was 348 individuals who maintained membership in the Society for Computer Applictions in Radiology which indicated interest in computer based interpretation systems (designated the "SCAR group").

The questionnaire was divided into five main sections: (1) six questions that obtained demographic information about the respondents; (2) eight questions that evaluated the importance attributed to presumed advantages of filmbased image interpretation; (3) six questions that evaluated the importance attributed to presumed advantages of CRTbased image interpretation; (4) 16 questions that evaluated the importance given to attributes of current and future display systems; and (5) 11 questions that evaluated how several factors affect radiologists' efficiency during interpretation sessions. Comments and advice were also solicited. Similar questionnaires were sent to both groups; they differed only in the demographic questions. Each question asked respondents to choose a single response among four graded categories. The Kolmogorov-Smirnov test ${ }^{9}$ was used to determine if there were any significant differences in choice frequency between the two groups. 
Table 1. Demographics for Practicing Radiologist and SCAR Group

\begin{tabular}{|c|c|}
\hline $\begin{array}{l}\text { PR Group } \\
(N=137)\end{array}$ & $\begin{array}{l}\text { SCAR Group } \\
(N=143)\end{array}$ \\
\hline \multicolumn{2}{|l|}{ Primary specialization (\%) } \\
\hline 76 General diagnostic & $\begin{array}{l}70 \text { Medicine (radiologists- } \\
\text { MD) }\end{array}$ \\
\hline 7 Digital imaging (CT, MRI) & $\begin{array}{l}3 \text { Medicine (nonradiologist- } \\
\text { MD) }\end{array}$ \\
\hline $\begin{array}{l}3 \text { Special procedures (CV, } \\
\text { Neuro) }\end{array}$ & 4 Computer science \\
\hline 12 Nuclear medicine & 8 Engineering \\
\hline 2 Ultrasound & 1 Psychology \\
\hline 0 Research & 14 Physics \\
\hline \multicolumn{2}{|l|}{ Experience $(\%)$} \\
\hline 1 Resident & 1 In graduate training \\
\hline 0 Fellow & 2 Post-doc or Fellow \\
\hline $10<5$ yr post-residency & $4<5 y r$ in medicine \\
\hline $2111-15$ yr post-residency & $2111-15 \mathrm{yr}$ in medicine \\
\hline $2116-20$ yr post-residency & $1916-20$ yr in medicine \\
\hline $23>20 \mathrm{yr}$ post-residency & $37>20 \mathrm{yr}$ in medicine \\
\hline
\end{tabular}

\section{RESULTS}

A total of 282 responses $(26.7 \%$ of the 1,056 total) were received and tabulated including $137(19.3 \%)$ from practicing radiologists and $145(41.6 \%)$ from the SCAR group. Tables 1 and 2 show demographic data from the two groups. As seen on Table 3, almost all (90\%) of the practicing radiologists indicated that they used film-based interpretation at least $75 \%$ of the time. Table 4 indicates that only about $9 \%$ of the SCAR group devoted greater than or equal to $50 \%$ of their time to computer-based imaging systems.

Because there was a substantial level of agreement among the PR and SCAR groups with respect to their attitudes about film-based, CRT-based and future display systems, their responses to these items were combined for ease of presentation. The responses to the

Table 2. Demographics: Primary Work Site

\begin{tabular}{lc}
\hline $\begin{array}{c}\text { PR Group } \\
(\mathrm{N}=136) \\
\text { Primary Practice Site } \\
(\%)\end{array}$ & \multicolumn{1}{c}{$\begin{array}{c}\text { SCAR Group } \\
(\mathrm{N}=142) \\
\text { Primary Employer } \\
(\%)\end{array}$} \\
\hline 73 Community hospital & 28 Community hospital \\
15 University teaching hospi- \\
tal
\end{tabular}

Table 3. Current Interpretation Practices

\begin{tabular}{cc}
$\begin{array}{c}\text { PR Group } \\
(\mathrm{N}=136)\end{array}$ & $\begin{array}{c}\text { Percent Exams } \\
\text { Read on Film }\end{array}$ \\
\hline 46 & 100 \\
44 & $100-75$ \\
8 & $75-50$ \\
1 & $50-25$ \\
0 & $25-0$ \\
1 & 0 \\
\hline
\end{tabular}

group of questions designed to evaluate the importance of presumed advantages of film over CRT-based reading, and vice-versa, are listed in Tables 5 and 6 . The results of the groups of questions designed to evaluate various attributes of current and future display systems are in Tables 7 and 8 , respectively.

There were significant differences in the responses between the practicing radiologists and the SCAR group regarding the presumed advantages of CRT over film, specifically: "access to other computerized information" $(P<.001)$ and "no problems with missing films" $(P<.001)$. The PR and SCAR groups also responded significantly differently in rating the value of various attributes of current display systems, specifically: "access to clinical data" $(P<.001)$ and "access to administrative information" $(P<.05)$. There were no other significant differences in the responses of the two groups.

The perceived reasons for inefficiencies in the CRT-based reading environment were tabulated. A total of $77 \%$ of all respondents felt that CRT display devices themselves impaired (55\%) or substantially impaired (22\%) efficiency. Other less frequently cited interruptions included: consultations with technologists, phone calls, and scheduling decisions; however, consultations with referring physicians and patient care decisions were thought to have little impact. A large fraction of respondents indicated that ambient light levels need to be carefully controlled, both

Table 4. Level of Interaction With PACS

\begin{tabular}{cc}
$\begin{array}{c}\text { SCAR Group } \\
(\mathrm{N}=144)\end{array}$ & $\begin{array}{c}\text { Fraction of Workload } \\
\text { Devoted to PACS }(\%)\end{array}$ \\
\hline 3 & 100 \\
3 & $100-75$ \\
3 & $75-50$ \\
12 & $50-25$ \\
56 & $25-0$ \\
23 & 0 \\
\hline
\end{tabular}


Table 5. Importance of Presumed Advantages of Film-Based Over CRT-Based Reading

\begin{tabular}{lcc}
\hline & \multicolumn{2}{c}{ Rating } \\
\cline { 2 - 3 } \multicolumn{1}{c}{ Presumed Advantage } & $\begin{array}{c}\text { Not Really an } \\
\text { Advantage or } \\
\text { Not Important } \\
(\%)\end{array}$ & $\begin{array}{c}\text { Important } \\
\text { or Very } \\
\text { Important } \\
(\%)\end{array}$ \\
\hline Film reading faster & 26 & 74 \\
CRT presently unavailable in many & & \\
$\quad$ facilities & 19 & 81 \\
$\begin{array}{l}\text { Easier to view many images } \\
\text { Films are better suited to reading }\end{array}$ & 16 & 84 \\
$\quad$ room environment & 62 & 38 \\
Films are portable & 38 & 62 \\
Film interpretation requires no spe- & & \\
$\quad$ cial computer skills & 76 & 24 \\
Films are reliable (no computer & & \\
$\quad$ down time) & 38 & 62 \\
Films are brighter & 80 & 20 \\
\hline
\end{tabular}

in film interpretation (76\%) and in CRT-based interpretation (64\%).

\section{DISCUSSION}

The demographic results of the survey demonstrate that the respondents-practitioners were a sample of general radiologists whose practice settings and experience were felt to be similar to those of all practicing radiologists. The favorable response rate suggests that there is interest in the computer-based interpretation and picture archiving and communications systems (PACS). Few of the SCAR group devoted much of their time to PACS. This may indicate that this targeted population was inappropriate, or that few people in this radiology community actually spend much time on PACS development. Although the SCAR sample was intended to reach a more sophisticated and specialized

Table 6. Importance of Presumed Advantages of CRT Reading Over Film-Based Reading

\begin{tabular}{llc}
\hline & \multicolumn{2}{c}{ Rating } \\
\cline { 2 - 3 } \multicolumn{1}{c}{ Presumed Advantage } & $\begin{array}{c}\text { Not Really an } \\
\text { Advantage or } \\
\text { Not Important } \\
(\%)\end{array}$ & $\begin{array}{c}\text { Important } \\
\text { or Very } \\
\text { Important } \\
(\%)\end{array}$ \\
\hline $\begin{array}{l}\text { Availability of quantitative informa- } \\
\text { tion }\end{array}$ & 36 & 64 \\
Access to the entire dynamic range & & \\
$\quad$ of information & 10 & 90 \\
Access to image processing & 26 & 74 \\
Access to other computerized infor- & & \\
$\quad$ mation & 33 & 67 \\
Access to cine mode & 50 & 50 \\
No problems with missing films & 32 & 68 \\
\hline
\end{tabular}

Table 7. Value of Various Attributes of Current Display Systems

\begin{tabular}{lccc}
\hline & \multicolumn{3}{c}{ Rating } \\
\cline { 2 - 4 } \multicolumn{1}{c}{ Attribute } & $\begin{array}{c}\text { Waste } \\
\text { of Time } \\
(\%)\end{array}$ & $\begin{array}{c}\text { Useful } \\
(\%)\end{array}$ & $\begin{array}{c}\text { Valuable or } \\
\text { Very Valuable } \\
(\%)\end{array}$ \\
\hline Adjustable gray scale & 1 & 12 & 87 \\
View images from different & & & \\
$\quad$ modalities & 5 & 27 & 68 \\
Magnify & 5 & 30 & 65 \\
View multiple images & 5 & 18 & 77 \\
Access to clinical data & 7 & 29 & 64 \\
Quick review of cases & 8 & 29 & 63 \\
Viewing by several individuals & 9 & 37 & 54 \\
Access to administrative & & & \\
$\quad$ information & 27 & 44 & 29 \\
\hline
\end{tabular}

group of scientists, this group was primarily composed of radiologists. A potential for error exists because no attempt to obtain a response from the nonresponders was performed. This would be required to ensure that the population who responded was representative of the entire sample (eg, that the group who responded was not biased for or against computer-based systems).

There were few significant differences in the responses of the two groups. The differential importance that the two groups attributed to "availability of other computerized information," "elimination of missing films," and "access to clinical and administrative information" could be the result of the SCAR group's greater familiarity with, and a broader perspective about, CRT-based systems. This may indicate that such information is less valuable in the day-today practice of radiology or, alternatively, that successful acceptance of CRT-based systems

Table 8. Value of Various Attributes of Future Display Systems

\begin{tabular}{lccc}
\hline & \multicolumn{3}{c}{ Rating } \\
\cline { 2 - 4 } \multicolumn{1}{c}{ Attribute } & $\begin{array}{c}\text { Waste } \\
\text { of Time } \\
(\%)\end{array}$ & $\begin{array}{c}\text { Useful } \\
(\%)\end{array}$ & $\begin{array}{c}\text { Valuable or } \\
\text { Very Valuable } \\
(\%)\end{array}$ \\
\hline Higher resolution monitors & 1 & 10 & 89 \\
Multi-CRT monitors & 5 & 16 & 79 \\
Workstations that process & & & \\
$\quad$ images & 6 & 34 & 60 \\
Overlap different modalities & 7 & 27 & 66 \\
Access to knowledge bases & 8 & 34 & 58 \\
3D displays & 16 & 44 & 40 \\
Color displays & 39 & 36 & 25 \\
"Pilot's helmet" & 58 & 26 & 16 \\
\hline
\end{tabular}


will require educating practicing radiologists about these capabilities.

The responses to this survey may help guide improvements in workstation design that will lead to greater acceptance and wider deployment of these systems. The most important perceived advantages of CRT-based interpretation were access to the entire dynamic range of image information and access to image processing. Attributes of existing display systems that should be considered for incorporation into future designs included an adjustable gray scale, ability to view multiple images, view images from different modalities, magnification, access clinical data, and allow quick review of cases. Potential advances that many respondents felt valuable were higher resolution monitors, multiple CRT monitors, the overlap of different modalities (allowing multi-modality display), and workstations that process images. The most important perceived disadvantages of CRT-based reading may be redressed in the future. Presumably the unavailability of CRTs could be eliminated with the development of less expensive systems. The ease and speed issues may become less important with increased familiarity and experience with CRT-based systems. The ability to view multiple images simultaneously appears to be a very important feature of the film-based systems, which will be needed in computerbased interpretation systems in future development. The requirement of computer skills did not appear to be a major drawback.

Film is a remarkably durable and reliable interpretation and display system and storage medium. It is available to even the most remote locations and is cost-effective for institutions that have very limited volumes. The information available on a single film is tremendous. The film-based interpretation system is so well established that it is likely that any new system must be very easy to interact with or be similar to film or it may never become widely used. Efforts to develop useful and efficient CRT-based interpretation systems should combine the most valued attributes of film-based reading with the valued attributes of CRT-based systems.

\section{ACKNOWLEDGMENT}

The authors gratefully acknowledge the assistance of John Pippke Judy and Lawrence Pippke Judy for data entry and Ms Susan McLaughlin for manuscript preparation.

\section{REFERENCES}

1. Wells PN: Display of visual information, in: Hendee WR, Wells PNT (eds): Visualization Science in Engineering, Computing and Medicine. An International Workshop Sponsored by the American College of Radiology. Reston, VA, American College of Radiology, 1988, pp 22-25

2. Huang HK, Rutherford HG, O'Hare J, et al: Ergonomics of the imaging workstation, in: Hendee WR, Wells PNT (eds). ACR report: Engineering Research in Visual Perception. Reston, VA, American College of Radiology, 1986

3. American National Standard for Human Factors Engineering of Visual Display Terminal Workstations: Santa Monica, CA, The Human Factors Society, 1988

4. Farrell RJ, Booth JM: Design handbook for imagery interpretation equipment. Seattle, WA, Boeing Acrospace Co, 1984, section 6.1-6.10
5. Pizer SM, Beard DV: Medical image workstations: Functions and implementation. J Digit Imag 2:185-193, 1989

6. Kazan B: New electronic displays and their possibilities for radiology. Invest Radiol 24:817-819, 1989

7. Foley DW, Jacobsen DR, Taylor AJ, et al: Display of CT studies on a two-screen electronic workstation versus a film panel alternator: Sensitivity and efficiency among radiologists. Radiology 174:769-773, 1990

8. Fisher P, Grover B, Brauer G, et al: Digital image display station performance requirements based on physician experience with a prototype system. J Digit Imag 2:150-155, 1989

9. Siegel S: Non-parametric statistics. New York, NY, McGraw-Hill, 1956 